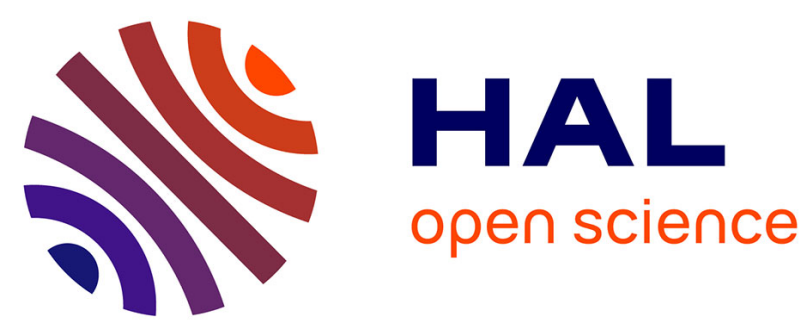

\title{
Suspended core tellurite glass optical fibers for infrared supercontinuum generation
}

I. Savelii, J.C. Jules, G. Gadret, B. Kibler, Julien Fatome, M. El-Amraoui, N. Manikandan, X. Zheng, F. Desevedavy, J.M. Dudley, et al.

\section{- To cite this version:}

I. Savelii, J.C. Jules, G. Gadret, B. Kibler, Julien Fatome, et al.. Suspended core tellurite glass optical fibers for infrared supercontinuum generation. Optical Materials, 2011, 33 (11), pp.1661-1666. 10.1016/j.optmat.2011.05.010 . hal-00655170

\author{
HAL Id: hal-00655170 \\ https://hal.science/hal-00655170
}

Submitted on 21 Apr 2021

HAL is a multi-disciplinary open access archive for the deposit and dissemination of scientific research documents, whether they are published or not. The documents may come from teaching and research institutions in France or abroad, or from public or private research centers.
L'archive ouverte pluridisciplinaire HAL, est destinée au dépôt et à la diffusion de documents scientifiques de niveau recherche, publiés ou non, émanant des établissements d'enseignement et de recherche français ou étrangers, des laboratoires publics ou privés.

\section{(c)(1)}

Distributed under a Creative Commons Attribution| 4.0 International License 


\title{
Suspended core tellurite glass optical fibers for infrared supercontinuum generation
}

\author{
I. Savelii ${ }^{\text {a }}$, J.C. Jules ${ }^{\text {a }}$, G. Gadret ${ }^{\text {a }}$, B. Kibler ${ }^{\text {a }}$, J. Fatome ${ }^{\text {a }}$, M. El-Amraoui ${ }^{\text {a }}$, N. Manikandan ${ }^{\text {a }}$, X. Zheng ${ }^{\text {a }}$, \\ F. Désévédavy ${ }^{\mathrm{a}}$, J.M. Dudley ${ }^{\mathrm{b}}$, J. Troles ${ }^{\mathrm{c}}$, L. Brilland ${ }^{\mathrm{d}}$, G. Renversez ${ }^{\mathrm{e}}$, F. Smektala ${ }^{\mathrm{a}, *}$ \\ a Laboratoire Interdisciplinaire Carnot de Bourgogne, UMR 5209 CNRS-Université de Bourgogne, 9 Av. A. Savary, 21078 Dijon, France \\ ${ }^{\mathrm{b}}$ Institut FEMTO-ST, UMR 6174 CNRS-Université de Franche-Comté, 25030 Besançon, France \\ ' Sciences Chimiques de Rennes, UMR 6226 CNRS-Université de Rennes I, 35042 Rennes, France \\ ${ }^{\mathrm{d}}$ Perfos, 11 rue Louis de Broglie, 22300 Lannion, France \\ e Institut Fresnel, UMR 6133 CNRS-Université d'Aix Marseille, 13397 Marseille, France
}

We report the fabrication and characterization of tellurite $\mathrm{TeO}_{2}-\mathrm{ZnO}-\mathrm{Na}_{2} \mathrm{O}(\mathrm{TZN})$ microstructured sus-pended core optical fibers (MOFs). These fibers are designed for infrared supercontinuum generation with zero dispersion wavelength (ZDW) at $1.45 \mu \mathrm{m}$. The measured losses at this wavelength are approxi-mately $6 \mathrm{~dB} / \mathrm{m}$ for a MOF with a $2.2 \mu \mathrm{m}$ diameter core. The effective area of a particular fiber is $3.5 \mu \mathrm{m}^{2}$ and the nonlinear coefficient is calculated to be $437 \mathrm{~W}^{-1} \mathrm{~km}^{-1}$. By pumping a $20 \mathrm{~cm}$ long fiber at $1.56 \mu \mathrm{m}$ with a sub-nJ femtosecond laser source, we generate a supercontinuum (SC) spanning over $800 \mathrm{~nm}$ in the $1-2 \mu \mathrm{m}$ wavelength range.

\section{Introduction}

During the last 20 years and more especially in the recent past years, soft oxide glasses have been involved into a stimulating research process because of their strong nonlinear optical properties, which are of great interest in view of broadband infrared laser sources and potential applications in diverse areas of science and technology [1-4]. In present time, mid-IR sources are based either on optical parametric oscillators, which require large lasers and can be rather complex, costly to maintain and hard to scale up in power, or on low power quantum cascade lasers for instance. The solution to these difficulties started to appear since the first report of broadband supercontinuum generation in microstructured optical fibers (MOFs) [5]. This type of fibers generated broad interest due to their unique guidance properties, high nonlinearities and dispersion management [6,7]. The use of MOFs for supercontinuum generation is particularly attractive since tight mode confinement can be realized increasing fiber nonlinearity and because the zerodispersion wavelength (ZDW) can be tailored to optimize supercontinuum generation for a given pump wavelength $[3,8]$.

At the same time we observe the development of new materials that combine desirable thermo-mechanical properties with good optical quality that are necessary conditions in order to get high performance lasers. Lots of works on glass composition have been

\footnotetext{
* Corresponding author. Tel./fax: +33 380396029 .

E-mail address: frederic.smektala@u-bourgogne.fr (F. Smektala).
}

reported in silicate, borate and phosphate glasses, but tellurite glasses deserve the greatest interest due to their potential for nonlinear optical devices. Wang et al. have established a detailed comparison of tellurite, silica, fluoride and chalcogenide glasses properties [9], Snitzer et al. have presented the compositions of glasses for fibers fabrication [10] and numerous glass compositions [11-13] have been developed for nonlinear optics.

Our goal is to acquire a good control of tellurite MOF fabrication and of their nonlinear optical properties for the development of efficient broadband laser sources in the mid-IR. We report here our first attempt in that field. We have fabricated tellurite MOFs from TZN glass and have carried out their optical characterizations. Robust guidance at $1.55 \mu \mathrm{m}$ was confirmed by optical measurement. We have then used a femtosecond (fs) pulsed laser at $1.56 \mu \mathrm{m}$ to pump a tellurite fiber presenting a ZDW around $1.45 \mu \mathrm{m}$ and an attenuation of $6.3 \mathrm{~dB} / \mathrm{m}$ at $1.55 \mu \mathrm{m}$ together with a quite small effective mode area $\left(A_{\text {eff }}\right)$ of $3.5 \mu \mathrm{m}^{2}$. By pumping a $20 \mathrm{~cm}$ long sample of this fiber, we observed an infrared supercontinuum generation expanded over $800 \mathrm{~nm}$ between 1 and $2 \mu \mathrm{m}$.

\section{Experimental}

\subsection{Glass preparation}

Tellurite bulk glass preforms were prepared using the following raw materials: tellurium (IV) oxide (Alfa Aesar, 99.99\%), zinc oxide 
(Alfa Aesar, 99.99\%), sodium carbonate (Alfa Aesar, 99.99\%). At this stage of our synthesis process, no additional in-house purification procedures were employed to reduce moisture or to eliminate trace levels of contaminants remaining in the commercial raw materials. Mixed batches were melted in platinum crucibles at $875^{\circ} \mathrm{C}$ for $1 \mathrm{~h}$, in an adequate ratio of raw materials corresponding to the molar composition $80 \% \mathrm{TeO}_{2}, 10 \% \mathrm{ZnO}, 10 \% \mathrm{Na}_{2} \mathrm{O}$ (TZN). We have chosen this composition because it shows a good potential for the drawing of nonlinear optical fibers [14]. In order to improve the homogeneity of the obtained glass, a stirring operation was carried out by opening the furnace and shaking the crucible during the glass melting process. The melts were poured in a brass mould preheated at $190{ }^{\circ} \mathrm{C}$ and subsequently annealed at approximately the glass transition temperature $\left(T_{g}\right)$ for $8 \mathrm{~h}$. Note that all the synthesis process was realized in room atmosphere. The glass samples were then cooled down slowly to room temperature. A typical batch weight was $70 \mathrm{~g}$. The obtained glass rods preforms were typically $7 \mathrm{~cm}$ long for a diameter of $16 \mathrm{~mm}$. These preforms were polished in view of fiber drawing. Small cylindrical slices were taken from them as spectral measurements samples.

\subsection{Thermal and optical properties of the glass}

Differential scanning calorimetry (DSC Q20 V24.4 Build 116) was used to determine the glass transition temperature $T_{g}$ and the crystallization onset temperature $T_{x}$ of the vitreous samples. The DSC curves were recorded in the $20-475{ }^{\circ} \mathrm{C}$ range at a constant heating rate of $10^{\circ} \mathrm{C} / \mathrm{min}$, in $\mathrm{N}_{2}$ atmosphere and at a constant gas flux of $50 \mathrm{ml} / \mathrm{min}$. Approximately $10 \mathrm{mg}$ of fine grain sample were used for measurements.

Four millimeter thickness slices were cut in the glass preforms and optically polished. The absorption spectra of the glasses were recorded at room temperature using an UV-VIS-NIR spectrophotometer (Perkin-Elmer Lambda 900) in the 200-1350 nm spectral range and a FTIR spectrophotometer (Perkin-Elmer Spectrum One) in the $1300-6700 \mathrm{~nm}$ range.

\subsection{Fiber design}

The aim of our investigation was to get a tellurite MOF able to generate an infrared supercontinuum. For that purpose, we experimentally pumped the fiber near its zero dispersion wavelength (ZDW) by means of a fs pulsed source at $1.56 \mu \mathrm{m}$. Thus it appeared necessary to downward shift the ZDW of the glass close to the pump wavelength with the help of an adequate MOF profile for which the waveguide dispersion is able to compensate for the material dispersion. Such a control of the chromatic dispersion can be obtained using two kinds of MOF profiles: the conventional one, based on a triangular lattice of holes and the suspended core one [15]. The former design requires many rings of air holes around the core to get guiding losses below material ones, even for high index glasses [16]. This implies a more complex preform fabrication and handling. Thus the suspended core profile was more suitable to reach our objective. Note that the dispersion slope of MOFs with large size air holes (much larger than the fiber core diameter) is larger than the dispersion slope of MOFs with small size air holes [17]. So, in this work, we have targeted tellurite MOFs with small air holes to reduce the dispersion slope in order to get a quite flattened SC [18].

\subsection{Fiber fabrication}

The fabrication of soft-glass microstructured optical fibers is a difficult process due to the narrow working temperature range and because of the necessity to realize a microstructured preform [19]. Very often, the stack-and-draw technique is used for that purpose. But this fabrication way presents many disadvantages and can lead to a poor optical quality of the microstructured preform. Typically, if we use the stack and draw procedure for a tellurite MOF fabrication, we encounter a glass surface degradation caused by handy manipulations, and the occurence of interstitial holes [20]. Thus, other techniques for tellurite MOFs fabrication have been developed by different research groups [21]. Here we have chosen an alternative technique that we have already successfully used for chalcogenide glass MOFs fabrication, and more precisely for the drawing of chalcogenide suspended core fibers $[15,22]$. Indeed, after annealing, the glass rod undergoes a mechanical machining in order to get three $0.8 \mathrm{~mm}$ diameter and $30 \mathrm{~mm}$ length holes surrounding a solid core (Fig. 1).

The prepared preforms were then drawn into fibers following the usual way. Many parameters were controlled during this process, such as preform temperature and translation speed, fiber drawing speed, pressure in the holes and flow rate of inert gas circulating along the preform. By selecting suitable sets of parameters, we could vary core, outer and holes diameter and obtain a complete control of fiber profiles. After fiber drawing, we have taken some pictures of the fibers core-sections with the help of a scanning electron microscope (SEM), in order to check the geometrical parameters of the fibers. Sections of several MOFs drawn from the preforms obtained using our mechanical machining technique are shown in Fig. 2a. These pictures allowed measurement of the core diameters, defined as the diameter of the circle inscribed in the triangular core. The fibers external diameters were around $85-130 \mu \mathrm{m}$ and core diameters varied within the range from 1.5 to $3 \mu \mathrm{m}$.

\section{Results and discussion}

\subsection{Thermal and optical properties of the glass}

To be considered as a suitable candidate for fiber drawing, the glass must have a good thermo-mechanical resistance to casting and a good stability against crystallization. This resistance to crystallization can be estimated by measuring the bulk glass thermal properties, its glass transition temperature $T_{g}$ and its crystallization temperature $T_{x}$. The difference between these values, $\Delta T=T_{x}-T_{g}$, provides a gauge of the glass resistance to crystallization, and should be as large as possible to ensure that the glass will form

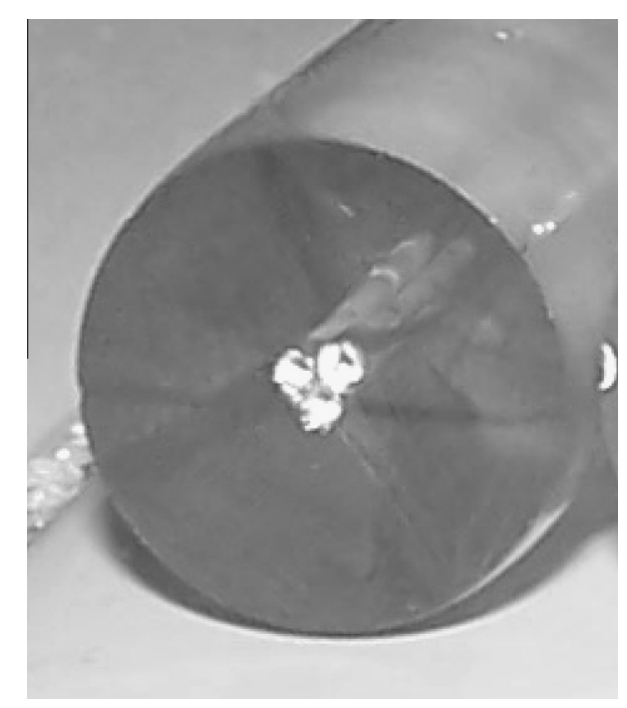

Fig. 1. Picture of a $16 \mathrm{~mm}$ outer diameter tellurite glass preform with three air holes around a solid core elaborated by mechanical manufacturing. 

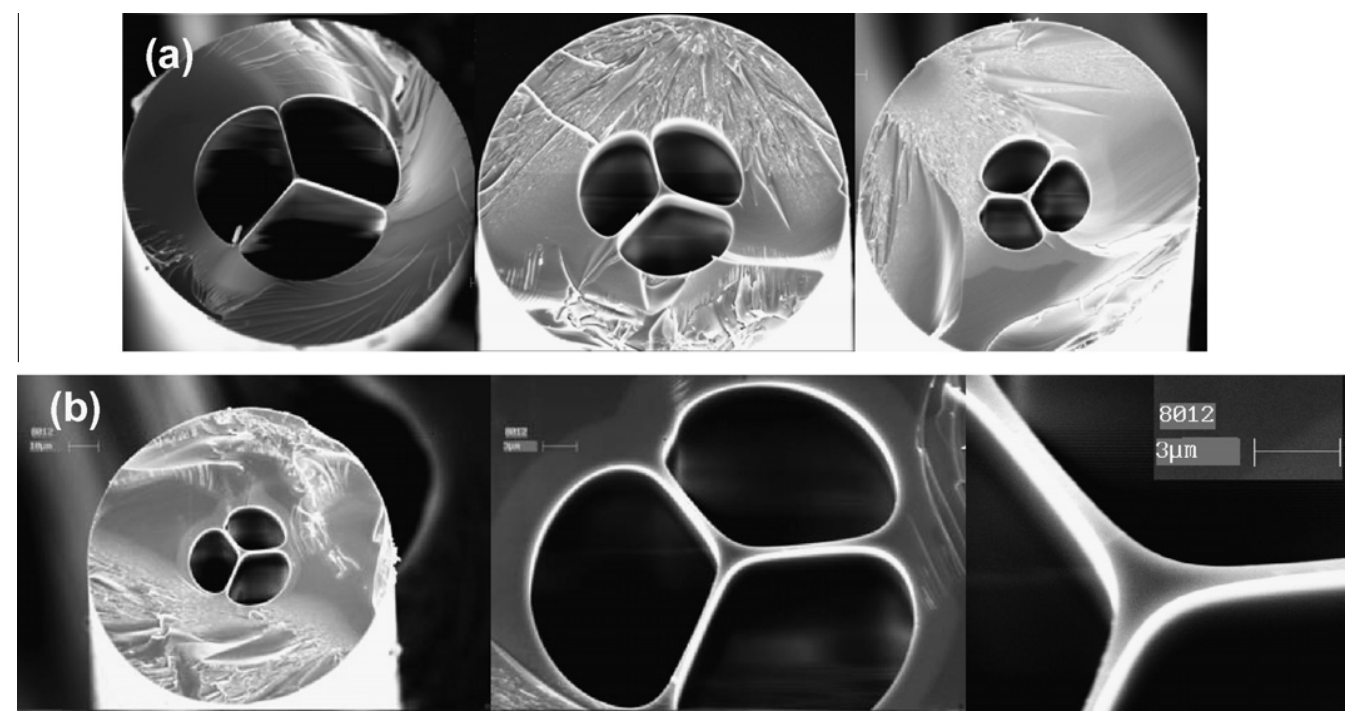

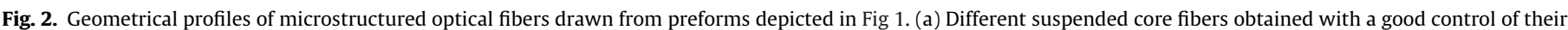

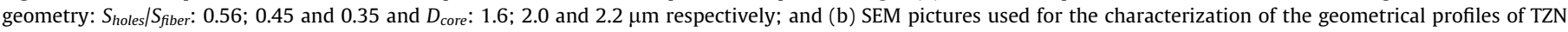
suspended core fibers.

good optical quality fiber with minimal scattering losses due to microcrystallites [23]. Typically, a $\Delta T$ value larger than $100^{\circ} \mathrm{C}$ leads to reasonable glass stability. As the preform must be hold within a heated furnace during drawing, this thermal stability becomes important for realizing crystallite-free fiber. Fig. 3 presents the differential scanning calorimetric (DSC) curve of our TZN glass. The small endothermic peak corresponds to the glass transition phenomenon $\left(T_{g}=285^{\circ} \mathrm{C}\right)$. The intense exothermic peak corresponds to a strong crystallization phenomenon with an onset crystallization temperature which cannot be determined with precision but which is above $500{ }^{\circ} \mathrm{C}$. The small exothermic peak for which $T_{x}=450{ }^{\circ} \mathrm{C}$ indicates an early crystallization stage of the sample.

Consequently, the glass thermal stability $\Delta T$ is over $150{ }^{\circ} \mathrm{C}$, which appears to be a suitable value, but the early crystallization stage $\left(T_{x}=450^{\circ} \mathrm{C}\right)$ could spoil the process of the fiber drawing. This early crystallization, which has not been observed for a similar composition [14], can be due to the fact that the DSC measurement is conducted on powder, which favors a surface crystallization.

The Fig. 4 shows the infrared absorption spectrum of TZN glass, exhibiting absorption bands in the infrared region due to hydroxyl $(\mathrm{OH})$ groups. Different $\mathrm{OH}$ bands are seen, their positions depending on the degree of $\mathrm{OH}$ hydrogen bonding ( $\mathrm{H}$-bonding) in the glass

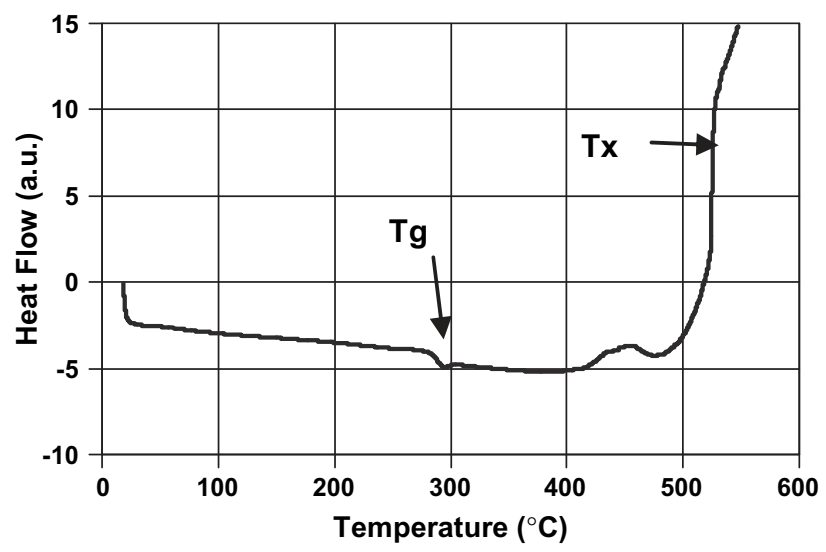

Fig. 3. DSC curve of TZN glass.

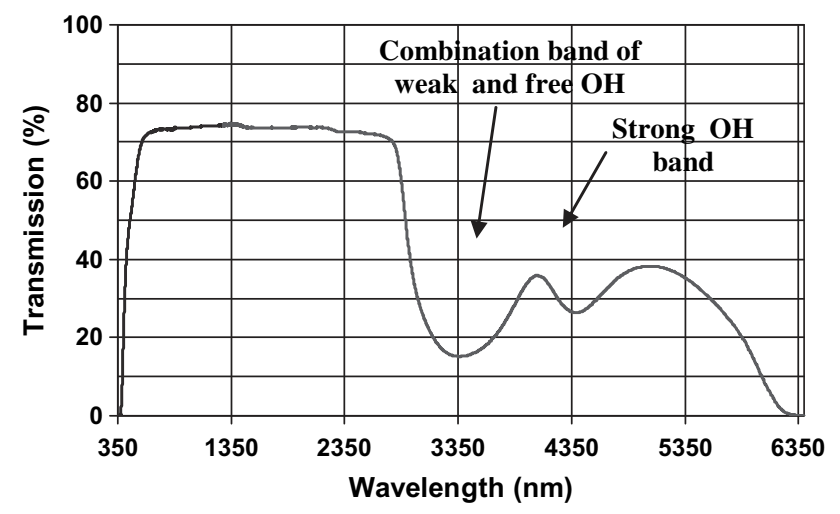

Fig. 4. Transmission spectrum of TZN glass.

[24]: strongly $\mathrm{H}$-bonded $\mathrm{OH}$ (strong $\mathrm{OH}$ ), weakly $\mathrm{H}$-bonded $\mathrm{OH}$ (weak $\mathrm{OH}$ ), and free $\mathrm{OH}$. A higher intensity asymmetric band is located around $3350 \mathrm{~nm}\left(2985 \mathrm{~cm}^{-1}\right)$, that is identified as a combination of weakly $\mathrm{H}$-bonded $\mathrm{OH}$ and free $\mathrm{OH}$. The lower intensity band at around $4350 \mathrm{~nm}\left(2300 \mathrm{~cm}^{-1}\right)$ is due to strongly $\mathrm{H}$-bonded $\mathrm{OH}$ in the glass. As shown in Fig. 4, the presence of $\mathrm{OH}$ absorption bands decreases the glass transmission for wavelengths over $3000 \mathrm{~nm}$. This is mainly due to the fact that the glass synthesis has been performed in room atmosphere, leading to a pollution of the glass with atmospheric moisture.

\subsection{Fiber design}

Using the SEM images of the tellurite MOFs core-sections (Fig. 2), we compute their dispersion curves using standard beam propagation method simulations [25]. As material dispersion curve data, we use the Sellmeier equations for two compositions close to our TZN glass, i.e. $80 \mathrm{TeO}_{2}-20 \mathrm{Na}_{2} \mathrm{O}$ (TeNa) and $75 \mathrm{TeO}_{2}-25 \mathrm{ZnO}$ (TeZn) in molar \% [26]. Fig. 5 presents the numerical prediction of the chromatic dispersion for two tellurite MOFs with a suspended core profile and a core diameter of $2.2 \mu \mathrm{m}$ similar to that of the fiber illustrated in Fig. 2b, calculated for both compositions. The ZDWs are shifted to lower wavelengths, around $1.45 \mu \mathrm{m}$, and their computed values for both compositions are very close. We 


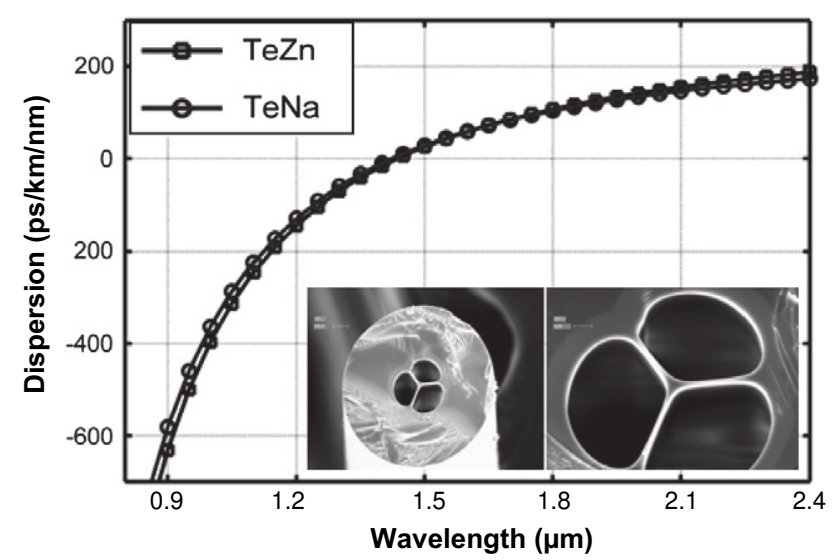

Fig. 5. Simulations of the chromatic dispersion curves for two tellurite glass MOFs from TeZn and TeNa compositions with a core diameter of $2.2 \mu \mathrm{m}$.

assume thus that the ZDW of our TZN suspended core fiber is close to $1.45 \mu \mathrm{m}$.

\subsection{Linear and nonlinear optical characterizations of tellurite MOFs}

After the fiber drawing process we observe the slight appearance of a weak surface crystallization of the fiber (Fig. 6) which leads to scattering defects. This is due to the drawing conditions (temperature, time and atmosphere) that are not yet optimized, with a drawing temperature close to the early crystallization stage (Fig. 3).

In order to characterize the guiding properties of our fibers, we start from optical losses measurements. Similarly to conventional optical fibers, the effective refractive index of the cladding is lower than that of the core due to the presence of air holes, ensuring core guiding of the light [27]. It is worthy to note that to ensure accurate core propagation measurements in our small core MOFs, the clad must be depleted from injected cladding modes. In this work, this

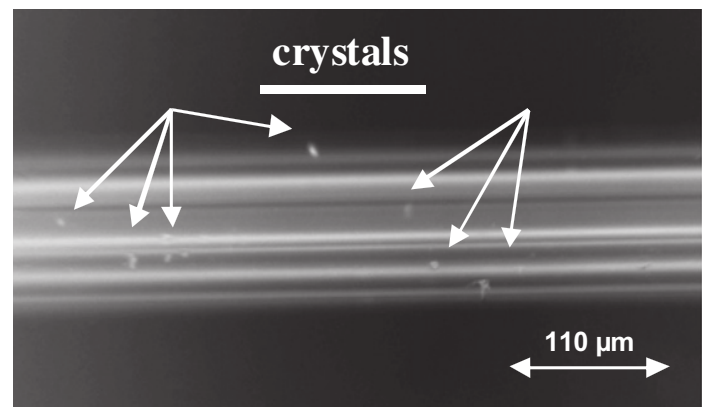

Fig. 6. Surface state of the TZN MOFs from SEM pictures. The bright points on the fiber surface correspond to the crystal, which can appear during fiber drawing. is systematically done by the deposition of an indium/gallium metallic alloy, liquid at room temperature, onto the fiber, thus leading to absorption of the evanescent waves related to clad propagation. Sequentially, to verify that the light propagates in the core of our microstructured fibers, we have imaged the output beam intensity distribution using a microscope objective and an infrared CCD camera. As shown in Fig. 7, the metallic coating leads to an output beam emitted from the core only. Thus, the slight surface crystallization which can be observed on the fiber will have no impact on the fiber losses, since the core propagating light doesn't interact with the outside surface of the fiber. Depending on their geometry, MOFs can support multimode or single-mode propagation. In our case, the theoretical calculations show that the drawn TZN MOFs are not rigorously single mode. However, the output profile, in the form of a Gaussian function whatever the chosen injection conditions, confirms single mode behavior (Fig. 7d).

The cutback method was employed to characterize the fiber optical losses [28]. The measurements were realized with the help of a FTIR spectrophotometer working in between $1 \mu \mathrm{m}$ and $2.2 \mu \mathrm{m}$ as well as using two discrete laser wavelengths at $1.06 \mu \mathrm{m}$ and $1.55 \mu \mathrm{m}$ for comparison. The results show that we get a typical attenuation curve for TZN single index fibers [28] with a minimum of losses around $1.55 \mu \mathrm{m}$ (Fig. 8). In the case of TZN MOF, the losses are measured at $1.06 \mu \mathrm{m}$ and $1.55 \mu \mathrm{m}$, since the core of these fibers is too small for direct FTIR injection. The measured losses of our $2.2 \mu \mathrm{m}$ diameter core TZN MOF at $1.55 \mu \mathrm{m}$ are $6.3 \mathrm{~dB} / \mathrm{m}$, consistent with the attenuation curve Fig. 8 . The suspended core is isolated from the external part of the fiber by three supporting struts, thus the light which is injected in the core is confined in this core and there is no interaction with the surface of the fiber. What is more, the eventual cladding modes are depleted by the application of a metallic alloy on the fiber surface. Thus, the surface crystallization has no influence on the suspended core fiber losses. What is more, the fact that the losses of the MOFs are comparable to the losses of the single index fibers indicates by the way that the surface degradation of the fiber is finally weak.

The losses of our single index TZN fibers are actually higher than that reported in other works $[9,14,29]$, but of the same order

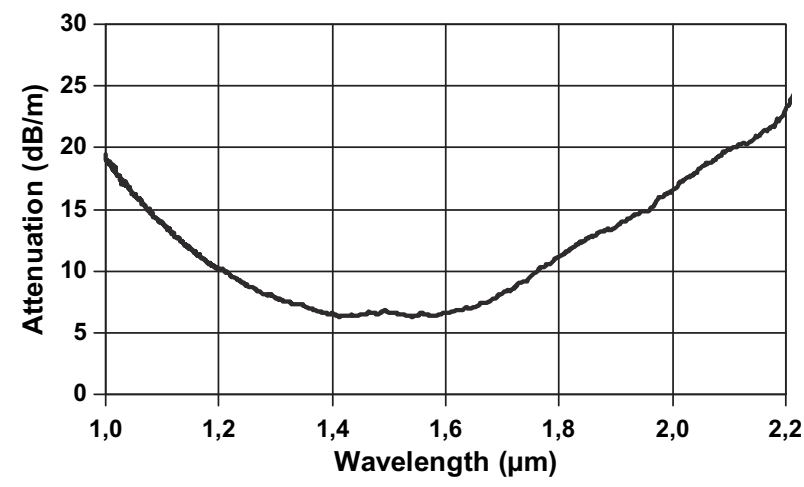

Fig. 8. Optical losses for a single index TZN fiber.
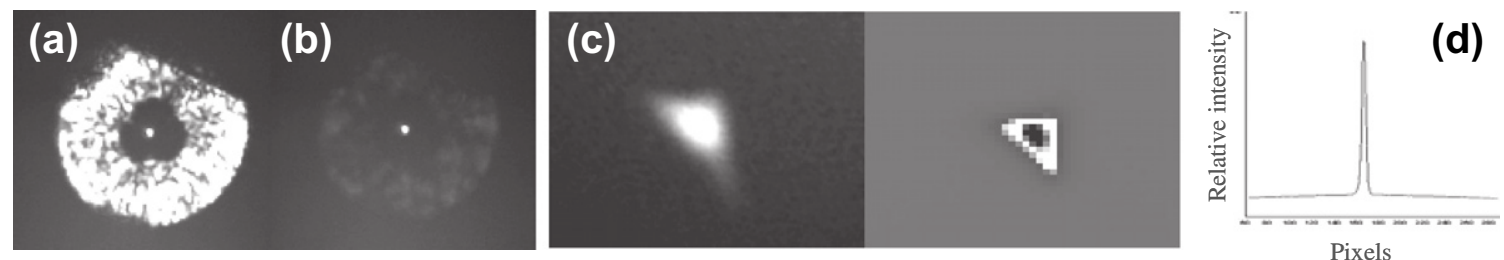

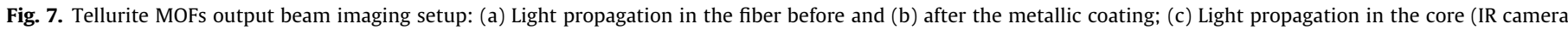
view); and (d) Mode profile of the output beam. 

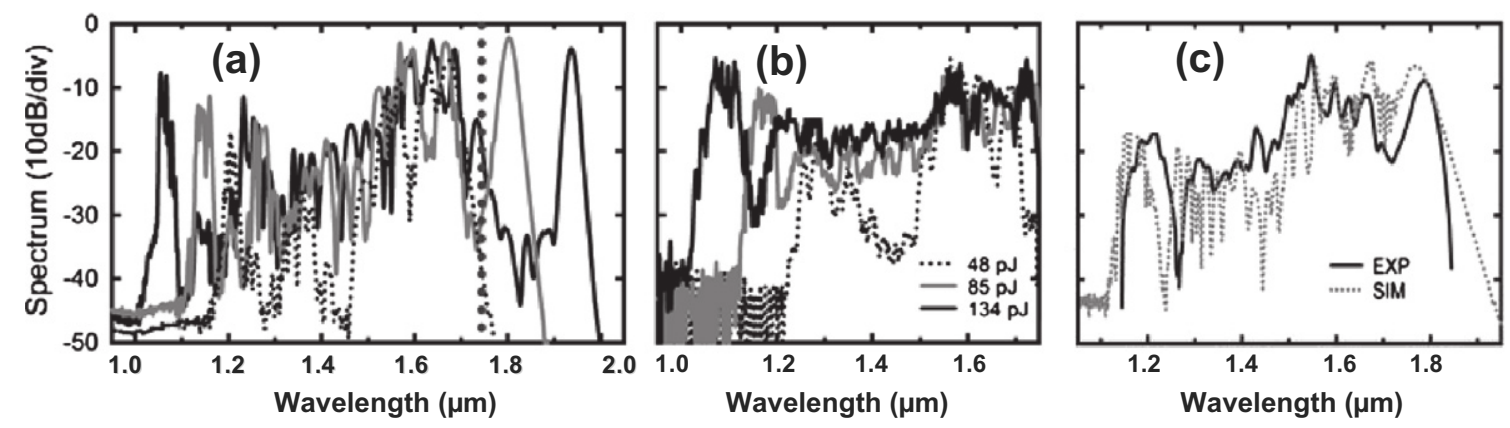

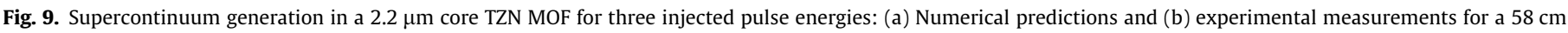

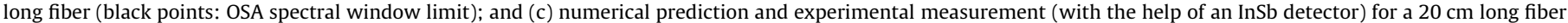
and a pulse energy of $80 \mathrm{pJ}$.

that TZN MOFs [21]. Note again that no purification stage of the glass was performed. This can explain the high losses values obtained for single index fibers. So, the losses may be significantly reduced by using optical-grade chemicals for forming the glass billets and by the improvement of the glass fabrication conditions. However, the fact that the losses for TZN MOFs are comparable to those of single index fibers indicates that no additional losses are induced by our preform fabrication process. This process is suitable for tellurite MOF fabrication as it is the case for chalcogenide MOF fabrication [15].

We have then carried out nonlinear optical characterizations by pumping the $2.2 \mu \mathrm{m}$ suspended core TZN MOF with a fibered femtosecond source delivering 100 fs pulses at $1.56 \mu \mathrm{m}$. The pump was injected into the TZN MOF and the output signal collected and analysed through an optical spectrum analyser (OSA) or with the help of a liquid nitrogen cooled InSb infrared detector. We have used two fiber lengths, $L_{1}=58 \mathrm{~cm}$ and $L_{2}=20 \mathrm{~cm}$, since the fiber characteristics correspond to an effective length of $50-60 \mathrm{~cm}$. At the same time we have performed numerical simulations based on the wellknown generalized nonlinear Schrödinger equation [30]. The model takes into account the numerical chromatic dispersion and the measured losses. It also includes Kerr effect (nonlinear Kerr coefficient is deduced from numerical calculation of effective area at $1.56 \mu \mathrm{m}: A_{\text {eff }}=3.5 \mu \mathrm{m}^{2}$ and $\gamma=437 \mathrm{~W}^{-1} \mathrm{~km}^{-1}$ ), self-steepening and Raman terms based on previous studies on tellurite glasses [14,31]. Numerical predictions (Fig. 9a) are compared to experimental spectra (Fig. 9b) for three distinct input pulse energies.

These spectra reveal a typical SC development which is connected with the dynamics of soliton propagation and break-up in the anomalous dispersion regime [30]. Namely, the initial stage of self-phase modulation is followed by pulse break-up and a subsequent soliton self-frequency shift (SSFS) towards longer wavelengths owing to intrapulse Raman scattering. Moreover, by pumping close to the ZDW, solitons generated in the anomalous dispersion regime shed energy into dispersive waves (DW) in the normal dispersion regime. We show that SC spectral broadening, as induced by both SSFS (long-wavelength edge) and DW generation (short-wavelength edge), grows progressively larger for increasing input power. However, our numerical simulations confirm that the limited spectral window of our analyser $(600-1750 \mathrm{~nm})$ prevents a complete observation of the spectral broadening. Indeed, the generated SC for the highest input energy just of $134 \mathrm{pJ}$ is expected to reach $2 \mu \mathrm{m}$, which gives a $1000 \mathrm{~nm}$ SC bandwidth. In order to confirm a SC enlargement above $1.75 \mu \mathrm{m}$, we used an InSb detector. Fig. 9c shows the numerical and experimental spectra obtained on a $20 \mathrm{~cm}$ long fiber. Both numerical and experimental spectra do not expand above $1.9 \mu \mathrm{m}$, due to the increasing losses in the infrared (Fig. 8), finally limiting the observed SC bandwidth at around $800 \mathrm{~nm}$.
During the course of the SC measurements, no physical damage to the fiber facets was observed, since we used low optical powers. We can note anyway that tellurites, with their smaller band gap than silica, generate low-density electron plasma more readily under strong optical excitation, thereby counteracting the self-focusing effect and preventing catastrophic optical damage [13,32].

\section{Conclusions}

We have fabricated and characterized microstructured suspended core tellurite fibers. A mechanical elaboration technique was applied for the preform fabrication. By selecting suitable sets of fiber drawing parameters we have been able to control the geometry. A $2.2 \mu \mathrm{m}$ diameter core fiber with a $3.5 \mu \mathrm{m}^{2}$ effective area has been pumped with a $1.56 \mu \mathrm{m}$ femtosecond source in its anomalous dispersion regime, the computed zero dispersion wavelength being located around $1.45 \mu \mathrm{m}$. An $800 \mathrm{~nm}$ supercontinuum has been obtained and found in good agreement with numerical predictions, thus confirming the computed dispersion properties. The limited SC expansion is attributed to fiber losses, due to the drawing of a non purified glass. These results anyway confirm the great potential of tellurite microstructured fibers for the efficient generation of a supercontinuum in the mid-infrared.

\section{Acknowledgments}

This work was supported by the Regional Council of Burgundy and by the French National Research Agency (NRA) through the project Confian "Supercontinuum using highly nonlinear infrared fibers".

\section{References}

[1] R. Holzwarth, T. Udem, T.W. Hansch, J.C. Knight, W.J. Wadsworth, P.S.J. Russell, Phys. Rev. Lett. 85 (2000) 2264-2267.

[2] I. Hartl, X.D. Li, C. Chudoba, R.K. Ghanta, T.H. Ko, J.G. Fujimoto, J.K. Ranka, R.S. Windeler, Opt. Lett. 26 (2001) 608-610.

[3] J.H.V. Price, T.M. Monro, H. Ebendorff-Heidepriem, F. Poletti, P. Horak, V. Finazzi, J.Y.Y. Leong, P. Petropoulos, J.C. Flanagan, G. Brambilla, X. Feng, D.J. Richardson, IEEE J. Sel. Top. Quantum Electron. 13 (2007) 738.

[4] V.L. Kalashnikov, E. Sorokin, I.T. Sorokina, Appl. Phys. B 87 (2007) 37-44.

[5] J.K. Ranka, R.S. Windeler, A.J. Stentz, Opt. Lett. 25 (2000) 25-27.

[6] J.C. Knight, T.A. Birks, P. St, J. Russell, D.M. Atkin, Opt. Lett. 21 (1996) 15471549.

[7] P. Russell, Science 299 (2003) 358-362.

[8] P. Domachuk, N.A. Wolchover, M. Cronin-Golomb, A. Wang, A.K. George, C.M.B. Cordeiro, J.C. Knight, F.G. Omenetto, Opt. Express 16 (2008) 7161.

[9] J.S. Wang, E.M. Vogel, E. Snitzer, Opt. Mater. 3 (1994) 187-203.

[10] E. Snitzer, E.M. Vogel, J.S. Wang, U.S. Patent, 1993, pp. 5251062

[11] M.R. Oermann, H. Ebendorff-Heidepriem, Y. Li, T.-C. Foo, T.M. Monro, Opt. Express 17 (18) (2009) 15578-15584.

[12] H. Li, J. Lousteau, W.N. MacPherson, X. Jiang, H.T. Bookey, J.S. Barton, A. Jha, A.K. Kar, Opt. Express 15 (2007) 8857-8863. 
[13] X. Feng, W.H. Loh, J.C. Flanagan, A. Camerlingo, S. Dasgupta, P. Petropoulos, P. Horak, K.E. Frampton, N.M. White, J.H.V. Price, H.N. Rutt, D.J. Richardson, Opt. Express 16 (18) (2008) 13651-13656.

[14] A. Lin, A. Zhang, E.J. Bushong, J. Toulouse, Opt. Express 17 (19) (2009) 1671616721.

[15] M. El-Amraoui, J. Fatome, J.C. Jules, B. Kibler, G. Gadret, C. Fortier, F. Smektala, I. Skripatchev, C.F. Polacchini, Y. Messaddeq, J. Troles, L. Brilland, M. Szpulak, G. Renversez, Opt. Express 18 (5) (2010) 4547-4556.

[16] F. Desevedavy, G. Renversez, L. Brilland, P. Houizot, J. Troles, Q. Coulombier, F. Smektala, N. Traynor, J.L. Adam, Appl. Opt. 47 (32) (2008) 6014-6021.

[17] B. Kuhlmey, G. Renversez, D. Maystre, Appl. Opt. 42 (4) (2003) 634-639.

[18] G. Quin, M. Liao, C. Chaudhari, Y. Arai, T. Suzuki, Y. Ohishi, J. Ceram. Soc. Jpn. 117 (2009) 706-708.

[19] L. Brilland, F. Smektala, G. Renversez, T. Chartier, J. Troles, T.N. Nguyen, N. Traynor, A. Monteville, Opt. Express 14 (3) (2006) 1280-1285.

[20] L. Brilland, J. Troles, P. Houizot, F. Desevedavy, Q. Coulombier, G. Renversez, T. Chartier, T.N. Nguyen, J.L. Adam, N. Traynor, J. Ceram. Soc. Jpn. 116 (1358) (2008) 1024-1027.
21] M. Liao, C. Chaudhari, G. Qin, X. Yan, T. Suzuki, Y. Ohishi, Opt. Express 17 (14) (2009) 12174-12182.

[22] M. El-Amraoui, G. Gadret, J.C. Jules, J. Fatome, C. Fortier, F. Désévédavy, I. Skripatchev, Y. Messaddeq, J. Troles, L. Brilland, W. Gao, T. Suzuki, Y. Ohishi, F. Smektala, Opt. Express 18 (25) (2010) 26655-26665.

[23] A. Soufiane, M. Poulain, J. Non-Cryst. Solids 161 (1993) 206-209.

$24]$ X. Feng, S. Tanabe, T. Hanada, J. Am. Ceram. Soc. 84 (2001) 165-171.

25] BeamPROP 8.1, RSoft Design Group, New York, 2008.

[26] G. Ghosh, J. Am. Ceram. Soc. 78 (10) (1995) 2828-2830.

[27] T. Pustelny, M. Grabka, Acta Phys. Pol. 114 (6A) (2008) A-115.

[28] I.P. Kaminow, L.W. Stulz, Appl. Phys. Lett. 33 (1978) 62.

[29] S. Shen, A. Jha, X. Liu, M. Naftaly, K. Bindra, H.J. Bookey, A.K. Kar, J. Am. Ceram. Soc. 85 (2002) 1391-1395.

[30] J.M. Dudley, G. Genty, S. Coen, Rev. Mod. Phys. 78 (2006) 1135-1184.

31] M.D. O’Donnell, K. Richardson, R. Stolen, C. Rivero, T. Cardinal, M. Couzi, D. Furniss, A.B. Seddon, Opt. Mater. 30 (2008) 946-951.

[32] J.B. Ashcom, R.R. Gattass, C.B. Schaffer, E. Mazur, J. Opt. Soc. Am. B 23 (2006) 2317-2322. 